\title{
A NEW ANTIBIOTIC, MACROMOMYCIN, EXHIBITING ANTITUMOR AND ANTIMICROBIAL ACTIVITY
}

\author{
Hideo Ghimura, Masaaki Ishizuka, Masa Hamada, Senil Hori, \\ Kyoko Kimura, Junko Iwanaga, Tomio Takeuchi and Hamao Umezawa \\ Institute of Microbial Chemistry, Shinagawa-ku, Tokyo
}

(Received for publication July 15, 1967)

\begin{abstract}
A macromolecular peptide was isolated from a culture filtrate of Streptomyces macromomyceticus $\mathrm{n}$. $\mathrm{sp}$. which is described in this paper. Macromomycin was isolated as a white powder by precipitation with ammonium sulfate, followed by dialysis, Dowex $1 \times 2$ column chromatography and Sephadex chromatography. It is a peptide with $\mathrm{Sw} 20$ value of 1.27 and a molecular weight of about 15,000 . It inhibits sarcoma 180 and mouse leukemia L-1210. It inhibits $S$. aureus, $M$. flavus, $S$. lutea, B. subtilis, and B. anthracis.
\end{abstract}

Culture filtrates of actinomycetes tested against L-1210, give much lower frequency of positive results than when tested on EHRLICH carcinoma. However, a culture inhibiting both EHrLich ascites carcinoma and L-1210 was found and the active agent was isolated. It is a macromolecular peptide which also inhibits the growth of Gram positive bacteria. This antibiotic was differentiated from neocarzinostatin and other known macromolecular peptides showing antitumor activity and was named macromomycin. Characteristics of the strain producing this antibiotic, processes of production and isolation, and properties of the antibiotic are reported in this paper.

\section{Characteristics of the Strain No. M 480-M 1}

The strain was isolated from a soil sample collected at Setagaya, Tokyo and was numbered M 480-M I. Colonies on CzapeK's agar medium containing glycerol

Plate 1. Spore surface of Streptomyces macromomyceticus n. sp. $(\times 8500)$

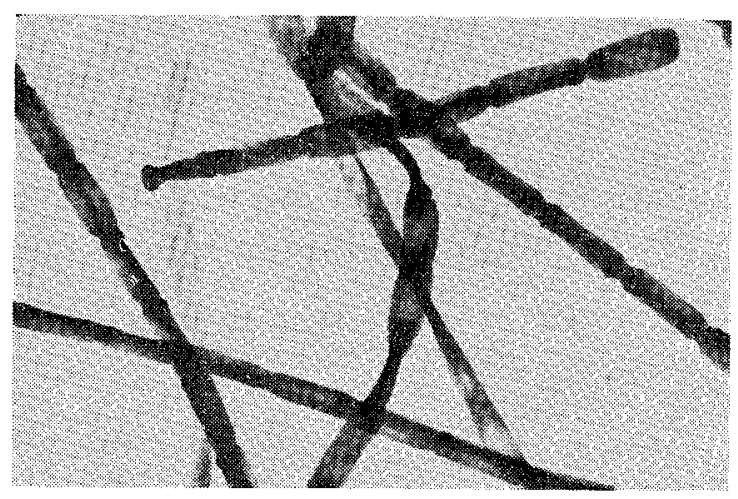
as the carbon source were examined microscopically. Long branched substrate mycelium of about $1 \mu$ in width and aerial hyphae were observed. Neither whorls nor spirals were observed. The surface of the spore was shown to be smooth by electron microscopy, as shown in Plate 1. The characteristics on various media are described below. The description in parenthesis follows the color standard published by Container Corporation of America. 
1. On glycerol Czapek's agar $\left(27^{\circ} \mathrm{C}\right)$ : Abundant greenish gray (Mistletoe Green $241 / 2$ li) growth; white to gray aerial mycelium; no soluble pigment.

2. On KRainsky's glucose asparagine agar $\left(27^{\circ} \mathrm{C}\right)$ : Grayish growth; no or white aerial mycelium; no soluble pigment.

3. On calcium malate agar $\left(27^{\circ} \mathrm{C}\right)$ : Colorless growth; white to brownish white aerial mycelium slightly; no soluble pigment; transparent zone around the growth.

4. In peptone water with $1.0 \%$ sodium nitrate $\left(27^{\circ} \mathrm{C}\right)$ : Colorless growth; no aerial mycelium; no soluble pigment; reduction of nitrate to nitrite.

5. On starch plate $\left(27^{\circ} \mathrm{C}\right)$ : Colorless to grayish growth; abundant brownish gray (Pussywillow Gray $5 \mathrm{dc}$ to Mauve Gray $8 \mathrm{ig}$ ) aerial mycelium; no soluble pigment; positive hydrolysis of starch.

6. On tyrosine agar $\left(27^{\circ} \mathrm{C}\right)$ : Dark brownish gray growth; white to brownish white aerial mycelium; black soluble pigment; positive tyrosinase reaction.

7. On potato plug $\left(27^{\circ} \mathrm{C}\right)$ : Abundant, wrinkled, greenish gray (Mistletoe Green $241 / 2$ li) to grayish yellowish brown (Mustard Tan $21 \mathrm{~g}$ ) growth; no or brownish white aerial mycelium; brownish soluble pigment.

8. On nutrient agar $\left(27^{\circ} \mathrm{C}\right)$ : Colorless to olive-gray growth; no aerial mycelium; no or slightly brown soluble pigment.

9. On nutrient agar $\left(37^{\circ} \mathrm{C}\right)$ : Colorless growth; no aerial mycelium; no soluble pigment.

10. On Loeffler's coagulated serum $\left(37^{\circ} \mathrm{C}\right)$ : Wrinkled colorless growth; no aerial mycelium; brownish soluble pigment; no liquefaction of coagulated serum.

11. On gelatin $\operatorname{stab}\left(20^{\circ} \mathrm{C}\right)$ : Colorless to brownish growth; no aerial mycelium; brown soluble pigment; liquefaction of gelatin in medium strength.

12. On skimmed milk $\left(37^{\circ} \mathrm{C}\right)$ : Colorless growth; no aerial mycelium; no soluble pigment; coagulation and peptonization of milk.

13. On cellulose $\left(27^{\circ} \mathrm{C}\right)$ : Poor growth; no hydrolysis.

14. Utilization of carbon sources on Pridham-Gottlieb basal medium $\left(27^{\circ} \mathrm{C}\right)$ : Abundant growth with glycerol, xylose, galactose, glucose, maltose, mannose, dextrin, starch, salicin; no or slight growth with fructose, lactose, sucrose; no growth with arabinose, rhamnose, dulcitol, inositol, mannitol, sorbitol, raffinose, inulin.

As shown by the characteristics described above, strain $\mathrm{M} 480-\mathrm{M} I$ belongs to Streptomyces and to the chromogenic type, though the production of brown soluble pigment is absent or slight in nutrient agar. It forms neither whorls nor spirals. The surface of the spores is smooth. The growth on various media is greenish gray, and the aerial mycelium is colored white to gray or white to brownish gray. No soluble pigment is formed in synthetic media but brown pigment occur frequently in organic media. Nitrate is reduced to nitrite. The proteolytic action is relatively weak and it hydrolyzes starch. Among known species, Streptomyces lydicus DE BoER et al. has many characteristics in common with strain M 480-M I. However, the property of the spore surface of this species has not been described. According to the description, S. lydicus forms buff to olive-tan growth, but no melanin pigment. In these points $S$. lydicus is different from strain $M 480-M 1 . S$. lydicus is known to produce streptolydigin. As described later, macromomycin is related to neocarzinostatin in antibacterial effect, antitumor effect and macromolecular nature. Streptomyces carzinostaticus ${ }^{1,8)}$ producing neocarzinostatin forms spores which have hairy projections. The strain No. M 480-M I was thus found to be different from known species and was designated Streptomyces macromomyceticus n. sp. HAMAdA et OKAMI. 


\section{Production, Isolation and Characters of Macromomycin}

Shaking cultures were fermented at 130 strokes per minute with $8-\mathrm{cm}$ in amplitude and $120 \mathrm{ml}$ of medium in $500-\mathrm{ml}$ flask. The strain $\mathrm{M} \mathrm{480-M} \mathrm{l}$ was shake-cultured for 48 hours and $2 \mathrm{ml}$ of the culture broth was inoculated to new medium. Tank fermentation was carried out in a $70 \mathrm{~L}$ stainless steel tank, which contained $40 \mathrm{~L}$ of medium. Eight hundred $\mathrm{ml}$ of 48 -hours shaking culture was inoculated. The tank was stirred at 300 r.p.m. and $40 \mathrm{~L}$ of sterile air was passed per minute. Soybean oil and silicon oil were used for antifoam.

Macromomycin was determined by a cylinder plate method using Micrococcus fiavus as the test organism. M. flavus was shake-cultured at $28^{\circ} \mathrm{G}$ for 48 hours in a medium containing $2.0 \%$ glucose, $1.0 \%$ meat extract, $1.0 \%$ peptone, and $0.3 \%$ sodium chloride. The $\mathrm{pH}$ was adjusted to 7.0 after sterilization. The medium employed for preparation of the plate contained $0.1 \%$ glucose, $0.6 \%$ peptone, $0.4 \%$ casamino acid, $0.15 \%$ meat extract, $0.3 \%$ yeast extract, and $1.0 \%$ agar and the $\mathrm{pH}$ was adjusted to 7.0 .

When strain M 480-M I was shake-cultured in a medium containing $1.0 \%$ glucose, $1.0 \%$ starch, $1.5 \%$ soybean meal, $0.1 \% \quad \mathrm{~K}_{2} \mathrm{HPO}_{4}, \quad 0.1 \% \quad \mathrm{MgSO}_{4} \cdot 7 \mathrm{H}_{2} \mathrm{O}, 0.3 \% \mathrm{NaCl}$, $0.0007 \% \mathrm{CuSO}_{4} \cdot 5 \mathrm{H}_{2} \mathrm{O}, 0.0001 \% \mathrm{FeSO}_{4} \cdot 7 \mathrm{H}_{2} \mathrm{O}, 0.0008 \% \quad \mathrm{MnCl}_{2} \cdot 4 \mathrm{H}_{2} \mathrm{O}$, and $0.0002 \%$ $\mathrm{ZnSO}_{4} \cdot 5 \mathrm{H}_{2} \mathrm{O}$ ( $\mathrm{pH}$ was adjusted to 7.0 ), then the culture filtrate after 4 days showed an inhibition zone of $24 \mathrm{~mm}$ diameter. A strain obtained by selection of productive spores produced $800 \mathrm{mcg} / \mathrm{ml}$ of macromomycin after 4 days of shaking culture in a medium similar to that described above except with $2.0 \%$ soybean meal. Macromomycin was precipitated by saturation with ammonium sulfate and separated from the salt by dialysis against water. The impurities could be separated from macromomycin by their adsorption on a cation exchange resin such as Dowex 1 X 2 or IRA400 in $\mathrm{Cl}^{-}$form. Active carbon was also usef ul to separate impurities. Macromomycin was purified by column chromatography using Sephadex G-50 or G-100. An example of the isolation is described below.

Nine liter of the cultured broth from shake flasks was filtered. The filtrate contained $2,700 \mathrm{mg}$ of macromomycin. To $8.5 \mathrm{~L}$ of the filtrate, $850 \mathrm{ml}$ of $50 \% \mathrm{ZnCl}_{2}$ aq. solution was added and filtered, and to $8.0 \mathrm{~L}$ of the filtrate, $5.5 \mathrm{~kg}$ of ammonium sulfate was added. After 3 hours at $5^{\circ} \mathrm{G}$ with occasional stirring, the precipitate containing macromomycin was separated by centrifugation at $4 \sim 5^{\circ} \mathrm{C}$. The precipitate was dissolved in $120 \mathrm{ml}$ of distilled water.

The solution, which contained $2,436 \mathrm{mg}$ of macromomycin, was placed in cellophane tubes and dialyzed against water for 12 hours at $5 \sim 10^{\circ} \mathrm{C}$. The solution thus obtained contained $1,950 \mathrm{mg}$ of macromomycin in $260 \mathrm{ml}$. The non-dialyzable solution was passed through a column $(4.0 \mathrm{~cm} \times 60 \mathrm{~cm})$ of Dowex $1 \times 2$ resin $(50 \sim 100$ mesh, $700 \mathrm{ml})$ in $\mathrm{Cl}^{-}$form. Then $2 \mathrm{~L}$ of distilled water was passed. The effluent from the column was fractionated into $50 \mathrm{ml}$ portions and those showing activity against $M$. flavus were collected. To the active solution $(700 \mathrm{ml}$ ) containing $1,260 \mathrm{mg}$ of macromomycin, $490 \mathrm{~g}$ of ammonium sulfate was added. The precipitate was collected and dissolved in $52 \mathrm{ml}$ of distilled water and dialyzed. The dialyzed solution (100 ml) containing 
$1,200 \mathrm{mg}$ of macromomycin was subjected to column chromatography $(5.3 \mathrm{~cm} \times 100 \mathrm{~cm})$ on Sephadex G-25 $(2.0 \mathrm{~L})$. The fractions containing macromomycin were collected, rapidly frozen, and lyophilized, yielding $600 \mathrm{mg}$ of powder of $60 \%$ purity. This powder was further purified by column chromatography $(3.5 \mathrm{~cm} \times 170 \mathrm{~cm})$ with Sephadex G-50 $(1.0 \mathrm{~L})$ and the active effluent $(270 \mathrm{ml})$ was diluted with distilled water to $810 \mathrm{ml}$, rapidly frozen, and lyophilized, yielding $340 \mathrm{mg}$ of pure macromomycin. Sephadex G-100 was also useful for purification of macromomycin.

Macromomycin is obtained as a white powder. It becomes brown at $240^{\circ} \mathrm{C}$, and decomposes with bubbling at $255 \sim 258^{\circ} \mathrm{C}$. It gives $[\alpha]_{\mathrm{D}}^{20}+119^{\circ}\left(\mathrm{c} 1, \mathrm{H}_{2} \mathrm{O}\right)$. It is soluble in water but insoluble in methanol, ethanol, butanol, acetone, ethyl acetate and benzene. The ultraviolet absorption shows $\mathrm{E}_{1 \mathrm{~cm}}^{1 \%} 8.2$ at $280 \mathrm{~m} \mu$ in $\mathrm{H}_{2} \mathrm{O}, \mathrm{E}_{1 \mathrm{~cm}}^{1 \%} 9.2$ at $284 \mathrm{~m} \mu$ in $0.1 \mathrm{~N} \mathrm{NaOH}$ and $\mathrm{E}_{1 \mathrm{~cm}}^{1 \%} 8.5$ at $278 \mathrm{~m} \mu$ in $0.1 \mathrm{~N} \mathrm{HCl}$, with a shoulder at $290 \mathrm{~m} \mu$ in all cases. The ultraviolet spectrum is shown in Fig. 1, and the infrared spectrum in Fig. 2.

It decolorizes permanganate and

Fig. 1. Ultraviolet absorption spectrum of macromomycin

gives positive FolIN-Lowry, EHRLICH, SAKAGUCHI and biuret reactions. Ninhydrin reaction is weakly positive. Molisch, ferric chloride, anthrone, Fehling, Tollen's and Benedict reactions are negative.

Pure macromomycin obtained by Sephadex G-50 this chromatography was subjected to the analysis by ultracentrifugation ${ }^{2,8)}$ at 59,780 r.p.m. The solution contained $0.93 \%$ of macromomycin. The pattern is shown in Plate 2 , indicating purity. The Sw 20 value was calculated to be 1.27 and analysis by ARCHIBALD's method indicated about 15,000 for the molecular weight.

Elementary analysis: C 43.89, H

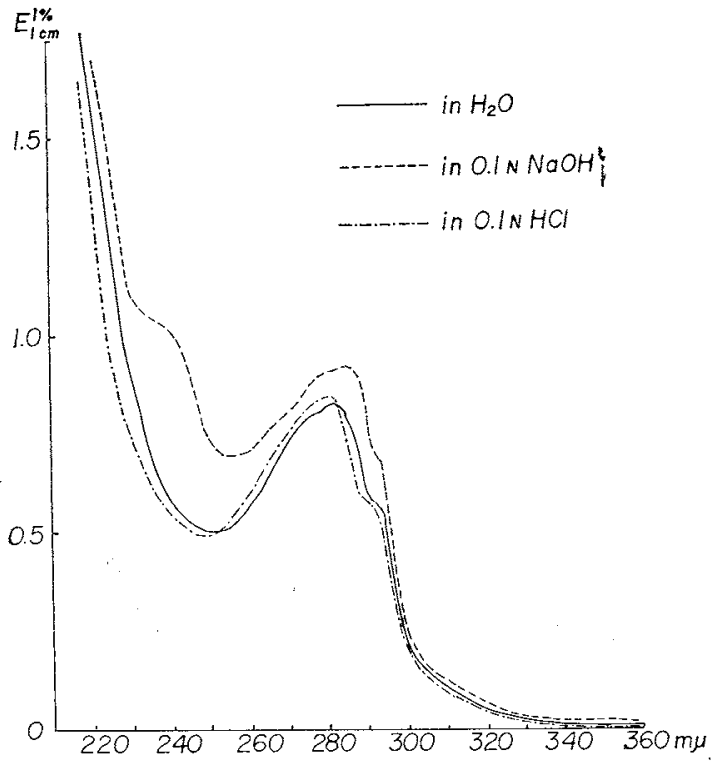

Fig. 2. Infrared absorption spectrum of macromomycin in $K B R$

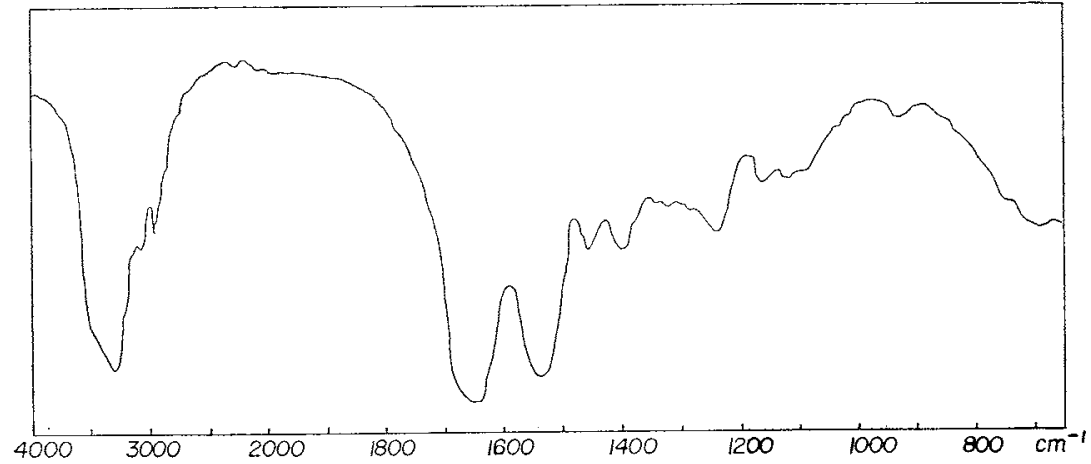


Plate 2. Ultracentrifuge pattern of macromomycin

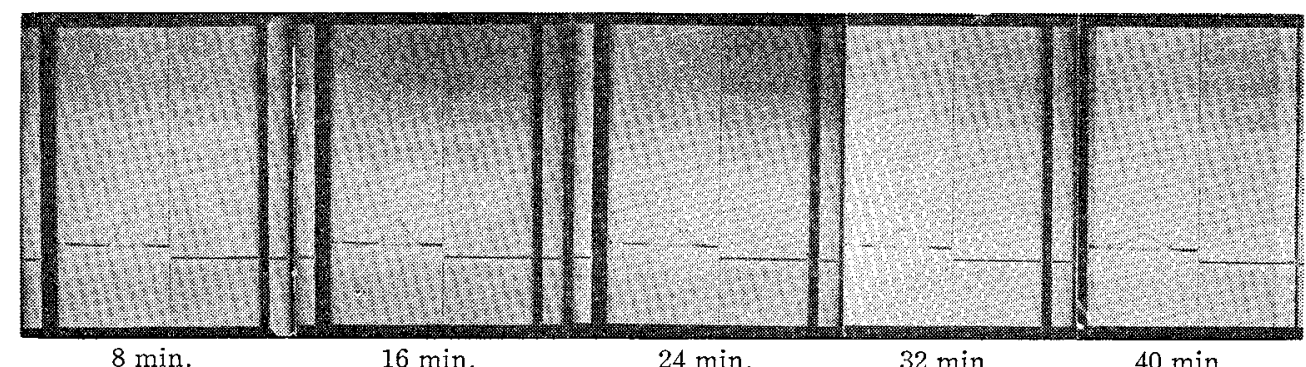

11.55, N 13.46, S 2.39, O 23.76. Tests for halogen and phosphor were negative. The following formula can be calculated for macromomycin: $\left(\mathrm{C}_{49} \mathrm{H}_{153} \mathrm{O}_{24} \mathrm{~N}_{13} \mathrm{~S}\right)_{8 \sim 10}$.

The amino acid analysis of the hydrolysate of macromomycin $\left(6 \mathrm{~N} \mathrm{HCl}, 105^{\circ} \mathrm{C}\right.$, 15 hours) indicated at least 15 amino acids. They are lysine, histidine, aspartic acid, threonine, serine, glutamic acid, proline, glycine, alanine, cystine, valine, isoleucine, leucine, tyrosine and phenylalanine.

On paper electrophoresis at $450 \mathrm{~V}$ for 4.5 hours in $\mathrm{pH} 8.6$ barbital buffer $(\mu=0.05)$ macromomycin moves toward the cathode $2.0 \mathrm{~cm}$. In $0.06 \mathrm{M}$ phosphate buffer at $\mathrm{pH}$ 6.8 , it moves $1.2 \mathrm{~cm}$ to cathode.

Macromomycin is not inactivated by trypsin and chymotrypsin in barbital buffer at $\mathrm{pH} 8.6(\mu=0.05)$ at $27^{\circ} \mathrm{C}$ for 24 hours. It is not inactivated by bacterial acid protease in $0.06 \mathrm{M}$ phosphate buffer at pH 6.8 for 24 hours at $27^{\circ} \mathrm{C}$. Macromomycin is inactivated by ultraviolet irradiation.

Table 1. Antibacterial spectrum of macromomycin

\begin{tabular}{|c|c|c|}
\hline & $\begin{array}{l}\text { Minimal inhibitory } \\
\text { concentration } \\
\text { in } \mathrm{mcg} / \mathrm{ml}\end{array}$ & Media* \\
\hline Staphylococcus aureus $209 \mathrm{P}$ & 1.56 & A \\
\hline "I $\quad$ Smith & 0.2 & " \\
\hline Sarcina lutea PCI 1001 & 0.01 & $" \prime$ \\
\hline Micrococcus flavus & $<0.05$ & $\prime \prime$ \\
\hline Bacillus subtilis NRRL 558 & 0.39 & $\|$ \\
\hline Bacillus anthracis & 0.2 & "f \\
\hline Salmonella enteritidis & $>100$ & "l \\
\hline Shigella flexneri la EW 8 & $>100$ & "l \\
\hline Proteus vulgaris ox 19 & $>100$ & "l \\
\hline Klebsiella pneumoniae PCI 602 & $>100$ & "l \\
\hline Escherichia coli NIHJ & 100 & $\prime \prime$ \\
\hline$\| \quad$ K 12 & 100 & $\prime \prime$ \\
\hline Serratia marcescens & $>100$ & $" \prime$ \\
\hline Pseudomonas aeruginosa A 3 & 100 & "t \\
\hline Pseudomonas fluorescens & 100 & $" \prime$ \\
\hline Xanthomonas oryzae & 100 & B \\
\hline Pyricularia oryzae & $>100$ & 11 \\
\hline Cryptococcus neoformans & 12.5 & $" 1$ \\
\hline Torula utilis & 1.56 & $\|$ \\
\hline Candida albicans $\mathrm{Yu}-1200$ & $>100$ & $\prime \prime$ \\
\hline Mycobacterium 607 & $>100$ & $\mathrm{C}$ \\
\hline Mycobacterium phlei & $>100$ & $\prime \prime$ \\
\hline
\end{tabular}

A: Nutrient agar medium, B: $1 \%$ glucose nutrient agar medium, $\mathrm{C}: 1 \%$ glycerin nutrient agar medium.
The antimicrobial spectrum is shown in Table I. It inhibits Staphylococcus aureus, Micrococcus flavus, Sarcina lutea, B. anthracis, $B$. cereus and $B$. subtilis at $0.05 \sim$ $1.56 \mathrm{mcg} / \mathrm{ml}$ and Xanthomonas oryzae at $100 \mathrm{mcg} / \mathrm{ml}$, but showed no inhibition of other bacteria in Table 1 at $100 \mathrm{mcg} / \mathrm{ml}$ except Torula utilis.

Mice tolerated the intravenous injection of $62.5 \mathrm{mg} / \mathrm{kg}$. The minimum effective dose against sarcoma 180 by daily intraperitoneal in jection was 3.9 $7.8 \mathrm{mcg} / \mathrm{mouse} /$ day and the daily injection of $250 \mathrm{mcg} / \mathrm{mouse} /$ day showed no toxicity. The daily injection of $40 \mathrm{mcg} /$ mouse/day prolonged the survival of mice intraperitoneally inoculated with 
L-1210 mouse leukemia; the survival time was $150 \%$ of the control.

Among known high molecular weight antitumor substances, neocarzinostatin has antibacterial activity and has been reported to be active against mouse leukemia L1210. Neocarzinostatin (Lot T-6-24) was easily differentiated from macromomycin by paper electrophoresis. Neocarzinostatin moved faster than macromomycin to cathode: $6.5 \mathrm{~cm}$ for neocarzinostatin and $2.0 \mathrm{~cm}$ for macromomycin under the conditions described above. Amino acid analysis of neocarzinostatin was reported ${ }^{4,5}$ to show no histidine, but macromomycin contains this amino acid. The $S_{w} 20$ value of neocarzinostatin has been reported to be 1.44 while macromomycin has a value of 1.27 . Marinamycin ${ }^{6,7)}$ was reported to be macromolecular and to show antibacterial activity. Marinamycin gives no peak in the ultraviolet spectrum, is not adsorbed on strongly acidic resin, and is precipitated with $\mathrm{ZnCl}_{2}$. Macromomycin shows maximum absorption at $280 \mathrm{~m} \mu$ in $\mathrm{H}_{2} \mathrm{O}$, is not observed in the effuent from a strongly acidic resin, and is not precipitated with $\mathrm{ZnCl}_{2}$. Thus, macromomycin is differentiated from the known antitumor substances.

\section{References}

1) ShoJ, J. : Preliminary studies on the isolation of carzinostatin complex and its characteristics. Studies on the streptomyces antibiotics. XXXXIII. J. Antibiotics, Ser. A 14(1):27 33, Jan. 1961.

2) Schachman, H. K. : U1tracentrifugation and related techniques (diffusion, viscosity) for molecular size and shape. Methods in Enzymology 4:52 65, 1957.

3) Tomma, S.: On ultracentrifugation. Kagaku-Kogyo-Siryo 30(2):68 82, 1961

4) Ishida, N. ; K. Miyazaki, K. Kumagai \& M. Rikimaru : Neocarzinostatin, an antitumor antibiotic of high molecular weight. Isolation, physicochemical properties and biological activities. J. Antibiotics, Ser. A 18(2): 68 76, Mar. 1965.

5) Maeda, H. ; K. Kumagai \& N. Ishida : Characterization of neocarzinostatin. J. Antibiotics, Ser. A 19(6) : 253 259, Nov. 1966.

6) Soeda, M.: Studies on marinamycin, an antitumor antibiotic substance. J. Antibiotics, Ser. B. $12: 300 \sim 304$, Aug. 1959.

7) Soeda, M. \& M. Miтомi : Chemical studies on marinamycin. II. Fundamental chemical studies on marinamycin. J. Antibiotics, Ser. A 15(4) : 182 186, July 1962.

8) The Society For Actinomycetes, Japan : Electron-micrograms of Actinomycetes, No. 1, 1965. 